\title{
A educação como socialização em Émile Durkheim
}

\author{
The education as socialization in Emile Durkheim \\ La educación como socialización en Émile Durkheim
}

\author{
Raquel Andrade Weiss* \\ Rhuany Andressa Raphaelli Soares ${ }^{* *}$
}

\section{Resumo}

O presente artigo tem como objetivo abarcar a centralidade da temática da educação na obra do sociólogo francês Émile Durkheim. Em um primeiro momento, pretende-se demonstrar de que forma o autor, a partir de sua concepção de ciência da educação, compreendeu o fenômeno educativo como fundamental tanto para a manutenção e a continuidade do meio social quanto para a formação dos indivíduos como membros de uma sociedade. Para Durkheim, a educação teria como função substancial transmitir o legado sociocultural de um determinado contexto, tendo como resultado um processo de socialização que possibilitaria a constituição do que ele denomina de "ser social". Por fim, apresentamos de que forma a educação dialoga diretamente com a questão da moralidade e seus elementos constitutivos e como os escritos durkheimianos sobre o tema se colocam como ponto de partida para pensar questões e problemáticas atuais sobre os processos educativos, tendo como exemplo o tema da diversidade.

Palavras-chave: educação; Émile Durkheim; socialização.

\section{Abstract}

This article aims to present the importance of the education subject in the work of the French Sociologist Émile Durkheim. At first, it is intended to show in which way the author, based on a science of education, sees the educational phenomenon as essential for both the maintenance of the social environment and the formation of individuals as members of society. Therefore, according to Durkheim, the educational process has the role of transmitting the sociocultural legacy of certain contexts, resulting in a socialization role that allows the creation of what he calls the social being. Finally, it will be demonstrated how education dialogues directly with the issue of morality and its constitutive elements and how the Durkheimian writings about the subject are a starting point for thinking about current issues and problems about educational processes of our times, such as the theme of diversity.

Keywords: education; Émile Durkheim; socialization.

Recebido em: 01/08/2020. Aprovado em: 16/12/2020

http://dx.doi.org/10.5335/rep.v28i1.11520

Bacharela em Ciências Sociais, mestra em Sociologia e doutora em Filosofia pela Universidade de São Paulo. Desde o ano de 2001, dedica-se à pesquisa da obra de Émile Durkheim, tendo escrito diversos artigos sobre o tema. Atualmente é professora associada do Departamento de Sociologia e professora permanente do Programa de Pós-Graduação em Sociologia da Universidade Federal do Rio Grande do Sul (UFRGS). Junto com Rafael Benthien, coordena o Centro Brasileiro de Estudos Durkheimianos e dirige a coleção "Biblioteca Durkheimiana", publicada pela EdUSP. Atua na área de teoria sociológica, sociologia da moral e, mais recentemente, tem pesquisado a relação entre Sociologia e Psicanálise. Orcid: https://orcid.org/0000-0002-5911-4147.E-mail: rhuany.soares@ufrgs.br

** Licenciada em Ciências Sociais pela Universidade Federal do Rio Grande do Sul (UFRGS) e mestranda do Programa de Pós-Graduação em Educação Profissional e Tecnológica do Instituto Federal do Rio Grande do Sul (IFRS). Atua na área de teoria sociológica e sociologia da educação a partir de estudos durkheimianos e bourdieusianos. Orcid: https:// orcid.org/0000-0002-8416-2036. E-mail: weiss.raquel@gmail.com 


\section{Resumen}

Este artículo tiene como objetivo abarcar la centralidad de la temática de la educación en el trabajo del sociólogo francés Émile Durkheim. Primero, se pretende demostrar cómo el autor, a través de la perspectiva de una ciencia de la educación, entendió el fenómeno educativo como algo fundamental tanto para el mantenimiento y la continuidad del entorno social como para la formación de los individuos como miembros de una sociedad. Por lo tanto, para Durkheim, entendemos que la educación tendría como una función sustancial la transmisión de todo el legado sociocultural de un contexto dado, dando como resultado un proceso de socialización que permitiría la constitución de lo que él llama ser social. Finalmente, se demostrará como la educación dialoga directamente con la temática de la moralidad y sus elementos constitutivos y cómo los escritos durkheimianos sobre el tema se colocan como un punto de partida para pensar los temas y problemas actuales sobre los procesos educativos, como la temática de la diversidad.

Palabras clave: educación; Émile Durkheim; socialización.

\section{Introdução}

Quando mergulhamos no universo dos escritos durkheimianos, percebemos que o conjunto de sua obra consegue abarcar uma diversidade de proposições sobre a realidade social, demonstrando que seus estudos não apenas poderiam auxiliar na compreensão do contexto em que o autor escreveu, mas podem fornecer uma base analítica para pensar questões do mundo contemporâneo.

Émile Durkheim, de forma geral, é conhecido como fundador e consolidador da Sociologia enquanto ciência, conferindo a esta seu objeto, seu fundamento e sua metodologia própria, distanciando-se das abordagens das ciências naturais. Ainda, além de demonstrar a construção de uma cientificidade das coisas sociais, Durkheim fortaleceu sua teoria sociológica por meio da aplicação desta em diversos campos de estudos.

As obras mais conhecidas do autor normalmente se relacionam com os escritos que buscavam fornecer uma base para a ciência que estava sendo institucionalizada, como podemos ver em As regras do método sociológico, ou, então, por exemplo, com as temáticas que tinham como preocupação "explicar os efeitos que as transformações modernas ocasionavam nos mecanismos de integração dos indivíduos na sociedade" (SELL, 2013, p. 87), destacando a obra Da divisão do trabalho social. No entanto, para além dos seus profundos interesses sobre a (formação da) ciência da sociedade como um todo - e de ser destacado no campo acadêmico predominantemente por esta razão -, podemos salientar um estudo específico, que foi investigado com igual importância, dedicação e originalidade, a saber, a educação. 
Ao longo da sua trajetória de vida pessoal e profissional, o sociólogo demonstrou grande preocupação com o fenômeno educativo e fez com que esta temática se tornasse central nas suas pesquisas.

Durkheim acreditava que, assim como a sociedade, a educação poderia e deveria ser estudada de forma científica. Desta forma, a educação também possuiria uma natureza própria, desenvolvida pelo seu caráter social, e deveria ser analisada pelos métodos e fundamentos da sociologia. Foi a partir desta concepção que a criação de uma Sociologia da Educação foi possível, fazendo com que Durkheim se tornasse o primeiro sociólogo da educação (FATURI, 2014, p. 13).

Assim, quando analisamos a educação investigada pelo autor, devemos compreender que esta dialoga diretamente com os fundamentos sociológicos apresentados por ele e, dessa forma, não pode ser dissociada de todo seu arcabouço teórico-metodológico.

Temos, então, que, de forma pioneira, Durkheim institui, pelo viés e olhar da Sociologia, uma área específica para esta temática - a Sociologia da Educação -, na qual a questão educacional aparece tanto como conceito sociológico, portanto, como um construto intelectual, quanto como processo social real, ou seja, ela se apresenta como um fenômeno de natureza eminentemente social, permitindo que sua compreensão seja feita desde a sua definição até a sua análise socio-histórica.

Sendo assim, conforme será apresentado, os estudos durkheimianos sobre educação se mostram fundamentais para entendermos o papel e as influências do fenômeno educativo no meio social e a forma como este auxilia na consolidação da sociedade e na construção daquilo que denominamos como ser social.

\section{A Ciência da Educação}

A constituição de uma ciência da sociedade e, mais ainda, de uma ciência da educação a partir de uma perspectiva sociológica, colocou-se como campo possível nos estudos durkheimianos devido à constituição do objeto da Sociologia, qual seja, o fato social. Esse conceito foi desenvolvido por Durkheim na obra As regras do método sociológico, e a forma como ele e suas características foram determinadas pelo autor são fundamentais para que compreendamos como a própria Sociologia e seus campos de estudo estabeleceram suas análises teóricas e empíricas, pois, com isso, "ele elevou o 'fator social' ao status de elemento básico e decisivo para explicar os fenômenos que tinham lugar no 'reino social”" (RODRIGUES, 2010, p. 29). 
Partindo de sua conceituação básica, os fatos sociais podem ser definidos como "maneiras de agir, pensar e de sentir exteriores ao indivíduo e dotadas de um poder coercitivo em virtude do qual se lhe impõem" (DURKHEIM, 2008b, p. 33). A partir dessa definição, já conseguimos extrair as características fundamentais do conceito e entender de que maneira ele dialoga com a realidade social.

Uma das primeiras qualidades distintivas do fato social é a sua generalidade, ou seja, partimos da ideia de que as representações e ações de uma dada realidade social se estendem e abrangem os indivíduos que nela estão inseridos. Assim, entendemos que o conceito durkheimiano tem como preocupação central a compreensão dos fenômenos e sistemas coletivos da sociedade, com aquilo que é comum a todos ou à grande parte dos seus membros. No entanto, devemos ter a clareza de que "um pensamento comum a todas as consciências particulares, ou um movimento repetido por todos os indivíduos, não é por isso um fato social" (DURKHEIM, 2008b, p. 35). A qualidade de generalidade terá como fundamento as crenças e as práticas do grupo tomadas coletivamente.

A segunda característica se refere à exterioridade do fato em relação às consciências individuais. Isso significa que "o comportamento social não procede do próprio indivíduo, mas de algo exterior [e anterior] a ele: a sociedade” (SELL, 2013, p. 83). Sendo assim, quando somos inseridos e começamos a fazer parte do meio social, toda estrutura material e simbólica já se encontra constituída e consolidada independente da nossa existência ou das nossas manifestações individuais.

Por fim, a terceira qualidade do fato social é sua ação coercitiva e imperativa, que abarca a força imposta pela sociedade ao indivíduo. Essa característica dialoga com a exterioridade, pois as regras, as condutas e os padrões sociais que garantem a manutenção de uma determinada sociedade já existem anteriormente e se interpõem ao sujeito independente da sua vontade. Percebemos isso de forma mais clara quando não seguimos as normas sociais: é nesses momentos que sentimos mais nitidamente sua pressão e a sanção - tanto legal quanto social - que decorre de seu descumprimento. Cabe salientar, ainda, que tal concepção não implica ausência de liberdade ou de autonomia do sujeito, mas supõe que toda ação transcorre em um meio social, que impõe resistência às ações que transgridam as expectativas e os padrões normativos do grupo.

A partir do entendimento do fato social como objeto de estudos da sociologia e das suas características como marco de separação dos fatos biológicos, físicos e psíquicos, passamos a compreender de que forma a educação se apresenta também como um fato social, já que se trata "de um fenômeno produzido pela vida coletiva, 
ou seja, de uma realidade social organizada ao longo dos séculos, caracterizada por um conjunto de práticas e instituições" (VARES, 2011, p. 31).

Neste momento, antes de entendermos o que seria a educação para Durkheim e a importância do seu papel social, é importante estabelecer uma diferenciação, realizada pelo próprio autor, que podemos inferir de seus escritos sobre o fenômeno educativo. Trata-se da distinção estabelecida entre o que seria a ciência da educação e o que seria a pedagogia.

Grosso modo, a sociologia da educação é concebida como uma ciência, voltada, portanto, à objetiva dos sistemas educativos: trata-se de buscar compreender de que modo se estruturam e operam os diversos sistemas educacionais em suas múltiplas dimensões. Está pressuposto que todas as coisas da educação são suscetíveis de observação e de estudo, e Durkheim propõe justamente uma concepção sociológica (científica) da educação, seja de sua natureza, seja de sua função. Nos termos de Paul Fauconnet (2013, p. 17), parte da primeira geração de autores que seguiram mais diretamente os preceitos durkheimianos, esta sociologia da educação teria como único fim "conhecer e compreender a realidade. [...]. A Educação é o seu objeto [e] devemos entender não que ela tenda aos mesmos fins que a Educação, mas, pelo contrário, que ela a supõe, visto que a observa”. A abordagem da ciência da educação deveria considerar os fatos educativos de forma relacionada com todas as dimensões da vida social, pois estes não existiriam isoladamente e só poderiam fazer sentido se fossem considerados como realmente são, ou seja, como fatos socialmente determinados e organicamente vinculados aos demais aspectos do sistema social mais amplo.

A pedagogia, na visão durkheimiana, teria preocupação central com aquilo que a educação deveria ser: seu objetivo não é tanto descrever ou explicar o que é ou o que tem sido a educação, mas determinar o que ela deve tornar-se. Ao contrário da ciência da educação, é investida de um caráter normativo, afinal, não tem o papel de nos dizer o que existe ou o porquê existe, mas de mostrar o que é preciso fazer. Portanto, a Pedagogia consistiria num conjunto de teorias cujo objetivo imediato seria orientar a conduta do educador. Seu verdadeiro fim não é a reflexão, mas a ação. Conforme Durkheim (2008a, p. 18), "a Pedagogia consiste, precisamente, em uma reflexão, a mais metódica e mais documentada possível, colocada a serviço da prática de ensino".

De forma resumida, "as teorias científicas têm como única finalidade exprimir a verdade, as teorias pedagógicas têm como objetivo imediato guiar a conduta. Se elas não constituem a ação propriamente dita, elas preparam a ação e nesse aspecto se aproximam dela" (DURKHEIM, 2008a, p 18). 
Com essas definições, entendemos que, mesmo que os objetivos dessas teorias se apresentem como diferentes, devem ser considerados como complementares e não excludentes. A ciência da educação pode e deve servir a finalidades práticas, e a pedagogia pode e deve utilizar-se dos conhecimentos produzidos pela sociologia, para que seus ideais possam corresponder à realidade e aos anseios da própria sociedade. Assim, a distinção entre sociologia e pedagogia, entre realismo e idealismo, não implica uma tensão insolúvel, mas uma relação necessária de complementaridade. Se à pedagogia caberia pensar as reformas e as práticas de ensino, ao sociólogo caberia compreender a educação de uma dada sociedade.

Dessa maneira, a demarcação entre essas duas atividades, longe de procurar opor uma à outra, consistiu justamente na proposição de certa divisão do trabalho intelectual com o intuito de articulá-las eficazmente. Vista sob esse ângulo, a demarcação proposta pelo autor foi fundamental para aproximá-las e não, como se poderia supor, distanciá-las. Isso porque, conforme observa Durkheim (2008a, p. 17), “essa distinção é necessária para que não se julgue as teorias pedagógicas mediantes princípios que não convêm senão às pesquisas propriamente científicas", assim, conforme prossegue o autor,

[...] a ciência deve preocupar-se em pesquisar com a maior prudência possível; ela não é forçada a obter algum resultado em um tempo definido. A pedagogia não tem o direito de ser tão paciente; porque ela responde a necessidades vitais que não podem esperar (DURKHEIM, 2008a, p. 17).

É importante notar que essa preocupação com a demarcação dos diferentes campos ou disciplinas é tributária da visão de ciência característica da França daquele período, assumindo contornos muito mais rígidos do que os vigentes contemporaneamente. Em todo caso, não deixa de ser importante extrair dessa concepção a ideia de que a transformação da educação é orientada por demandas práticas que não podem submeter-se aos parâmetros temporais do conhecimento científico, conquanto não deva prescindir deste. Em outros termos, isso significa que os sujeitos comprometidos com a transformação e a implementação de princípios e práticas educacionais não precisam ser os mesmos que se dedicam ao processo de compreensão das várias dimensões do sistema educacional existente. Ao mesmo tempo, o estabelecimento de um modelo educacional seria tanto mais efetivo e pertinente quanto mais baseado nos conhecimentos produzidos pelas diversas ciências, sobretudo a ciência da educação.

Ao considerar analiticamente a distinção entre o estudo do fenômeno educativo no âmbito da ciência da educação proposta por Durkheim e das teorias pedagó- 
gicas, podemos analisar a visão do autor acerca da definição da educação, do seu papel social e do seu caráter enquanto fato social.

\section{A natureza e a função do fenômeno educativo}

Durkheim formulou a noção de educação tanto por um viés lógico quanto ontológico, ou seja, suas análises englobavam tanto a definição de conceitos dentro deste campo de estudos quanto juízos acerca da natureza e função da questão educativa. Muitos estudiosos de diversas correntes ideológicas já haviam apresentado suas proposições sobre o que seria a educação, trazendo em suas análises características idealistas ou individualistas. No entanto, para Durkheim, quando definimos a educação "é preciso levar em consideração os sistemas educativos que existem ou que já existiram, compará-los e identificar aspectos em comum" (DURKHEIM, 2013 , p. 49). Tal argumento reitera os princípios metodológicos fundamentais de sua sociologia, que supõem que a definição de um fenômeno permita abarcar todas as formas socialmente existentes. Trata-se de um procedimento indutivo em que as caraterísticas gerais e recorrentes, presentes na multiplicidade empírica do fenômeno, são mobilizadas com intuito de se chegar a uma definição de um fato social especifico, no caso, a educação.

A partir de seus estudos teóricos e empíricos sobre a educação, seus processos e sistemas, um dos primeiros aspectos destacados pelo autor é o caráter social do fenômeno. A educação, além de conter as características de um fato social, podendo ser observada, analisada e comparada, apresenta-se como:

[...] algo eminentemente social e não individual, [pois] se constitui e se modifica conforme às necessidades de uma sociedade e não de indivíduos particulares. Assim, a partir das necessidades e dos fins que a educação atende, de suas mudanças de acordo com o tempo e espaço aos quais ela está inserida e da sua própria natureza, podemos constatar o caráter social que esta possui (FATURI, 2014, p. 36).

Entendemos, com isso, que a concepção de educação não poderia partir de uma noção ideal ou individual. A questão educacional está diretamente relacionada e terá correspondência com o contexto ao qual ela pertence e atenderá às necessidades específicas de uma sociedade. Esta noção nos leva a entender uma primeira característica da natureza do processo educativo: este se apresenta, ao mesmo tempo, como uno e múltiplo dentro do espaço social.

A educação pode ser entendida, em um primeiro momento, como una a partir do momento em que percebemos que qualquer tipo de educação, de acordo com seu 
contexto específico, repousa "sobre uma base comum. [Assim], não há povo em que não exista certo número de ideias, sentimentos e práticas comuns que a educação deve inculcar em todas as crianças sem distinção" (DURKHEIM, 2013, p. 51). Desta forma, a sociedade possui um determinado legado sócio-histórico e cultural que deve ser internalizado nas novas gerações, através de uma educação comum a todos, fazendo com que o meio social em questão seja preservado.

O caráter múltiplo da educação pode ser compreendido de duas formas. A primeira destaca a heterogeneidade existente em uma sociedade, abarcando as diferentes funções sociais e fazendo com que a diversidade de profissões se constitua em "um meio sui generis que demanda aptidões e conhecimentos específicos, um meio no qual predominam certas ideias, usos e maneiras de ver as coisas" (DURKHEIM, 2013, p. 51). Neste sentido, os diferentes tipos de educação corresponderiam às diferentes especializações que a sociedade necessitaria para se manter.

A segunda encontra-se amparada nas inúmeras diferenças sociais existentes, pois, conforme coloca Durkheim (2013, p. 20), “a [educação] da cidade não é igual à do campo [e] a do burguês não é igual à do operário”. Essa afirmação pode assumir um caráter um tanto polêmico em virtude do modo como é interpretada, pois muitas vezes é tomada como expressão de uma visão defendida pelo autor, como se estivesse sugerindo que a educação deve reproduzir as formas de desigualdade social. Todavia, aqui é preciso lembrar que se trata de uma concepção que busca compreender como a educação efetivamente opera e de que a educação está a serviço da reprodução do modo de vida social, que implica também os ideais sociais de cada época. O que a sociologia pode - e deve - fazer, contudo, é diagnosticar inconsistências entre o sistema educacional existente, a estrutura social e as aspirações de uma época. Para adiantar o exemplo com o qual trabalharemos ao final, em uma sociedade múltipla e complexa como a nossa, estruturada sobre valores constitucionais como o respeito à pessoa humana, caberia à sociologia identificar todos os aspectos do sistema educacional que estão em desacordo com esses princípios. Esse seria seu quinhão no processo de transformação social, fornecendo elementos para que a pedagogia possa propor diretrizes educacionais mais adequadas a esses valores, que contemplem a um só tempo a igualdade de direitos e o respeito à diversidade dos modos de vida. Ou seja, uma sociedade desigual reproduz-se a si mesma mediante um sistema educacional desigual; uma sociedade igualitária, por seu turno, só pode efetivar-se com um sistema educacional igualitário, o que não significa, porém, um sistema homogeneizante. 
Sendo assim, percebemos que a educação tem a prerrogativa de manter, ao mesmo tempo, uma homogeneidade e uma heterogeneidade entre os membros da sociedade - fato que garante a existência da vida coletiva. Isso significa que, "se, por um lado, existem tantas espécies de educação quanto meios sociais, por outro, todos os sistemas educativos difundem certos ideais e sentimentos comuns a todos os grupos sociais" (VARES, 2008, p. 84).

De forma resumida, temos que:

[...] cada sociedade elabora um certo ideal do homem, ou seja, daquilo que ele deve ser tanto do ponto de vista intelectual quanto físico e moral; que este ideal é, em certa medida, o mesmo para todos os cidadãos; que a partir de certo ponto ele se diferencia de acordo com os meios singulares que toda sociedade compreende em seu seio. É este ideal, único e diverso ao mesmo tempo, que é o polo da educação (DURKHEIM, 2013, p. 52).

Além desta dupla caracterização sobre o fenômeno educativo à luz da teoria durkheimiana, uma outra compreensão deve ser levada em consideração e destacada quando buscamos apreender essa temática de forma sociológica. Em diferentes obras, Durkheim demonstrou que no decorrer da nossa inserção do meio social podemos perceber a existência de dois seres que nos compõem, um sendo constituído pelo ser individual e outro pelo ser social, que apesar de se apresentarem de forma distinta são, na realidade, indissociáveis.

O ser individual seria caracterizado por todos os estados físicos e mentais que dizem respeito a nós mesmos, ou seja, que correspondem à nossa natureza - são as características imanentes aos indivíduos. Sendo assim, este ser demonstra e refere-se àquilo que é inato, distinguindo-se daquilo que é adquirido. Já o ser social é definido como "um sistema de ideias, sentimentos e hábitos que exprimem em nós não a nossa personalidade, mas sim o grupo ou os grupos diferentes dos quais fazemos parte" (DURKHEIM, 2013, p. 54). Este ser não nasce com o indivíduo e muito menos se constitui de forma natural. Ele é fruto da incorporação e internalização dos elementos sociais, culturais e históricos de uma determinada sociedade.

Quando começamos a fazer parte do meio social toda estrutura cultural, política, moral e simbólica já se encontra estabelecida naquele contexto. A forma de sermos integrados e correspondermos a este espaço dependerá justamente da formação deste ser social dentro de nós. Com isto podemos inferir que acontece uma via de mão dupla com a criação deste ser. A primeira corresponderia à inserção de cada indivíduo na sociedade, fazendo com que ele se torne apto a integrar esta, e a segunda que faria com que o meio social em questão fosse mantido, já que seu lega- 
do seria incorporado nos seus membros, ou seja, "os produtos do trabalho de uma geração deixam assim de serem perdidos pela geração seguinte" (DURKHEIM, 2013, p. 60), sendo desnecessário um constante recomeço por parte da sociedade. A partir deste entendimento, podemos destacar a importância e o foco que a questão educativa tem para Durkheim.

A educação, para o sociólogo, teria como objetivo e fim a constituição do ser social em cada um de nós. "Com exceção de tendências vagas e incertas que podem ser atribuídas à hereditariedade, ao entrar na vida, a criança traz apenas a sua natureza de indivíduo" (DURKHEIM, 2013, p. 55), sendo assim, a cada nova geração o meio social tem como preocupação a transmissão de todos os elementos estruturais e simbólicos que o compõe. O papel da educação será justamente garantir essa transmissão, possibilitando a formação de um novo ser, que é diferente e que irá substituir "o ser egoísta e associal que acaba de nascer por um outro capaz de levar uma vida moral e social” (DURKHEIM, 2013, p. 55). Temos em um momento, então, o homem em seu estado de natureza, antes de ser educado, e em outro aquilo que Durkheim irá considerar como sendo a verdadeira humanidade do homem, aquela para a qual a educação contribui para realizar, "o indivíduo [como] resultado de um desenvolvimento social e histórico" (JONES, 2016, p. 86).

Assim, percebemos que a função da educação é a criação do ser social e que esta ação ocorre de forma contínua na sociedade. Cada nova geração que começa a fazer parte de um contexto social desconhece as ideias e práticas compartilhadas neste, "a cada nova geração, a sociedade se encontra em presença de uma tábula quase rasa sobre a qual ela deve construir novamente" (DURKHEIM, 2013, p. 55). A educação, neste sentido, será aquela capaz de internalizar no indivíduo todos os sentimentos, ideias e valores, em resumo, todo o conhecimento acumulado da sociedade da qual ele faz parte. Em outras palavras, segundo a definição de Durkheim (2013, p. 53-54),

[...] a educação é a ação exercida pelas gerações adultas sobre aquelas que ainda não estão maduras para a vida social. Ela tem como objetivo suscitar e desenvolver na criança um certo número de estados físicos, intelectuais e morais exigidos tanto pelo conjunto da sociedade política quanto pelo meio específico ao qual ela está destinada em particular.

Neste âmbito, a educação, de forma geral, pode ser compreendida como o meio de socialização dos indivíduos. A construção desta socialização acontece ao longo das trajetórias de vida de cada um dos membros da sociedade e se molda na medida em que nos envolvemos com diferentes grupos sociais. A partir disso, podemos distinguir duas formas de socialização, a primária e a secundária. A pri- 
meira diz respeito ao início da nossa vida enquanto sujeito, ela "ocorre quase que inteiramente no âmbito da família ou da escola maternal, sucedâneo da família" (DURKHEIM, 2008a, p. 33) e abrange os primeiros processos educativos aos quais somos submetidos. Neste momento, que acontece durante a infância, iniciamos a internalização do mundo social e passamos a perceber suas normas e costumes. Ainda, é na socialização primária que começamos a ter contato com os primeiros indivíduos, já socializados, que acabam transmitindo sua realidade e sua visão de mundo, conduzindo a nossa identificação no espaço social.

A socialização secundária inicia "na escola primária, quando a criança começa a sair do círculo familiar e [passa] a se inserir no meio que a circunda" (DURKHEIM, 2008a, p. 33). Aqui já entendemos que a criança se encontra em parte socializada, no entanto, este segundo tipo de socialização mantem-se ao longo da vida e corresponde ao processo de inserção e envolvimento dos indivíduos em diferentes grupos e esferas sociais, incluindo aqui os diferentes níveis escolares. A partir do momento em que saímos de um espaço mais restrito e íntimo, como o meio familiar, e passamos a adentrar espaços sociais mais amplos e diversos, como o trabalho, a igreja, círculos de ativismo, grupos de amigos, etc., internalizamos e apreendemos as características e aspectos gerais destes espaços ou de seus membros. Desta forma, a cada relação ou conexão que estabelecemos com um novo grupo passamos a ser socializado por ele. A socialização secundária, então, acaba sendo mutável ao longo da vida e depende dos tipos e graus de envolvimento e laços sociais que os indivíduos se submetem na sua trajetória.

É importante destacar que as formas de socialização e o processo educativo, na maioria das vezes, ocorre sem que tenhamos total objetividade ou clareza sobre eles. Isso quer dizer que existe uma educação consciente, que é quando os costumes, as práticas e os valores são transmitidos intencionalmente, com o claro propósito de ensinar algo às crianças, mas também existe uma educação inconsciente, que ocorre de maneira não intencional. Este processo de intencionalidade também pode ser percebido na forma de apreensão e internalização individual, em que, em determinados momentos, nos colocamos dispostos a introjetar alguns aspectos sociais, enquanto em outros, isso ocorre de maneira mais naturalizada.

Além disso, devemos pontuar que os processos de socialização também podem existir de duas maneiras: formal e informal. A educação formal é aquela que tem lugar nas instituições destinadas a este fim e é marcada por práticas e rituais aos quais são submetidas todas as crianças de forma intencional. Essas instituições são socialmente reconhecidas por como instâncias legítimas e responsáveis por formar 
os indivíduos em conformidade com os mais importantes valores de tal sociedade ou grupo, sendo incumbidos de transmitir seus conhecimentos e princípios.

Em cada sociedade e em cada momento histórico, a educação formal foi sempre muito diferente. Em algumas tribos, por exemplo, a educação formal pode ter sido atribuída aos rituais de luta, ou de alguma dança, que todos deveriam aprender em alguma idade. O próprio rito de passagem, que também é bastante diferenciado nas várias culturas, consiste num tipo de educação, enquanto se trata sempre de um teste que deve provar que o indivíduo aprendeu as coisas necessárias, podendo agora ingressar numa nova etapa da vida social.

No caso da educação formal da sociedade ocidental contemporânea, por exemplo, as instituições têm como objetivo ensinar determinados conteúdos e disciplinas e, por vezes, determinadas formas de tratamento. Entretanto, percebemos que os responsáveis por esta educação também podem tornar estéreis os ensinamentos transmitidos de forma consciente, quando não seguem na prática aquilo que ensinam.

A educação informal acontece em espaços não formalizados para este fim, ainda que exista uma intencionalidade na transmissão, tais como igrejas, associações e partidos políticos. No caso da educação informal também percebemos as formas de socialização quando em uma família, por exemplo, a mãe ensina a seus filhos como se portar à mesa ou o porquê é importante comer determinados alimentos. Porém, os pais também ensinam a seus filhos, sem que percebam, como devem andar, como devem falar ou como deve ser o relacionamento entre os indivíduos. Aqui temos uma educação informal que se dá de forma não intencional ou não consciente, cujos efeitos também são decisivos sobre os sujeitos em processo de formação.

De qualquer forma, aquilo que é fundamental observar é que em todas essas ocasiões a educação implica sempre um determinado modo transmissão, na medida em que por meio de ações, palavras e ensinamentos a criança interioriza os valores, as ideias, os modos de agir, de falar e de pensar característicos da sociedade em que vive, conformando-se às normas sociais.

De forma muito didática em seus escritos, Durkheim fez questão de esclarecer que esta visão de educação/socialização não coloca o indivíduo de forma resignada ou passiva frente aos anseios da sociedade. Diferente dos animais, estimulados a desenvolverem instintos latentes ou tendências do seu organismo natural, a complexidade da vida humana exige uma ação exterior que não se limite "a reforçar tendências naturalmente marcantes, [...] ou seja, desenvolver potencialidades ocultas que só estão esperando para serem reveladas" (DURKHEIM, 2013, p. 55). 
Devemos entender que foram os próprios indivíduos, ao longo da sua evolução e do desenvolvimento dos seus conhecimentos, que tiveram a necessidade de constituir a sociedade enquanto tal e de criar meios para que ela se consolidasse e se perpetuasse. A educação e todo seu processo, neste sentido, correspondem aos anseios de um contexto, demonstrando que o indivíduo "só sentiu a sede do saber quando a sociedade a provocou nele, e a sociedade só a provocou quando ela mesma sentiu essa necessidade" (DURKHEIM, 2013, p. 57). Com isso, compreendemos e ressaltamos a complementariedade que existe na relação indivíduo-sociedade, que longe de se mostrarem como antagônicos, um acaba implicando o outro. Tudo o que somos enquanto membros da sociedade ou enquanto ser social foi nos dado pelos processos de socialização. Nossa identificação enquanto sujeito, nossas vontades e hábitos, nosso desenvolvimento, nossa forma de comunicação, nossos costumes e nossas visões de mundo foram possibilitadas porque fomos incorporados a um meio social e internalizamos aquilo que a vida coletiva tem de mais fundamental. Assim, caso não nos apropriássemos daquilo que a sociedade tem a oferecer, seriamos reduzidos a uma condição primitiva, afinal,

[...] o objetivo e o efeito da ação que [a sociedade] exerce sobre [o indivíduo], principalmente através da educação, não são nem um pouco reprimi-lo, diminuí-lo, desnaturá-lo, mas sim amplificá-lo e transformá-lo em um ser verdadeiramente humano (DURKHEIM, 2013, p. 60).

Com intuito de compreensão mais aprofundada desta discussão e como forma de ampliação do entendimento acerca do fenômeno educativo para Durkheim, devemos abarcar outro elemento desenvolvido e investigado pelo autor que dialoga diretamente com os apontamentos apresentados até o momento, qual seja, a moral.

\section{A educação moral e seus elementos}

A questão da moralidade foi tratada por Durkheim de forma muito aprofundada e complexa e coloca-se como discussão central quando tratamos o fenômeno educativo. Assim como seus estudos sobre a educação, o autor procurou entender as bases do conceito de moral, desenvolvendo o caráter histórico da moralidade, sua definição, seu papel social e seus elementos constitutivos, ou seja, Durkheim a apreendeu também como um fato social.

Neste sentido, partimos da ideia de que a moral não emana das consciências individuais, mas é colocada como algo cuja origem é exterior ao indivíduo, na medida em que ela existe objetivamente na sociedade. Assim, quando tratamos da mo- 
ral durkheimiana, não tratamos de enunciados imperativos, isto é, não indicamos aquilo deve ou não deve ser feito, como se fossem em si pronunciamentos morais, mas a compreendemos a partir de pronunciamentos declarativos, isto é, juízos que apenas descrevem o que é a moral em uma sociedade em um momento determinado. Isso significa que o estudo da realidade moral se apresenta, neste caso, sob um aspecto puramente objetivo.

A partir da concepção de Durkheim podemos entender a moral como tudo aquilo "que é fonte de solidariedade, tudo o que força o homem a contar com outrem, a reger seus movimentos com base em outra coisa que não os seus impulsos" (DURKHEIM, 2010, p. 420). Em outras palavras, a moral de uma sociedade se apresenta como um conjunto de máximas, um conjunto de regras de conduta "investidas de uma autoridade especial em virtude da qual são obedecidas, pelo fato de que elas ordenam" (DURKHEIM, 1970, p. 43-44).

De maneira genérica, é possível afirmar que a moral pode ser compreendida em um sentido mais amplo e em um sentido mais restrito. No sentido mais amplo, a moral pode ser definida como um conjunto de regras que garantem a existência de uma sociedade. Isso porque, na medida em que são compartilhadas por seus membros, tais regras determinam um padrão normativo para a ação e a coesão social. No sentido mais restrito, a moral é apenas um tipo particular de regra, uma regra que é ditada pela sociedade e que existe para a sociedade. É um conjunto de prescrições que definem o que um indivíduo deve ou não deve fazer. Em ambos os casos, elas consistem "em uma infinidade de regras especiais, precisas e definidas, que fixam as condutas dos homens nas diversas situações que se apresentam cotidianamente" (DURKHEIM, 2008b, p. 40)

Como pode ser notado, a articulação entre as definições de moral, ampla ou restrita, envolve duas ordens de questões de caráter mais analítico, quais sejam, as regras e os valores. Usualmente, é comum que se entenda que regras seriam algo diverso de valores. As regras apareceriam como impositivas e exigiria certo sacrifício, enquanto os valores seriam atrativos, que, com ânimo e espontaneidade, a eles nos dedicaríamos. Contudo, no pensamento durkheimiano, regras e valores não se diferenciariam radicalmente; representariam apenas graus diferentes de adesão e condicionamento à moral. Essa diferenciação está na base da distinção entre moral no sentido amplo - considerada como regras e valores - e moral no sentido restrito - que se refere apenas à dimensão coercitiva da regra. Essa perspectiva é crucial para a forma com que o autor percebe a vida social. 
Cotidianamente, as regras e os valores podem aparecer para nós como aspectos bastante distintos, na medida em que pela categoria "regras" entendemos imposições alheias a nossa vontade, mas às quais obedecemos para evitar a pena que decorre de sua não obediência. Em suma, entendemos a regra como uma restrição à nossa liberdade. Por outro lado, a categoria "valor" implica tudo aquilo que prestigiamos, que desejamos e que nos esforçamos para conquistar ou para manter. Num contexto mais amplo, são os valores compartilhados pelos membros de uma sociedade que incitam uma ação comum em defesa dessa ou daquela causa, que nos levam a ter as mesmas crenças, os mesmos gostos, conferindo, assim, uma identidade própria a cada sociedade. Vistos dessa forma, os valores aparecem como a expressão de uma escolha, como afirmação da própria liberdade de agir segundo os próprios valores, não segundo valores que nos são estranhos ou imperativos.

Entretanto, conforme nos revela a teoria durkheimiana, os valores possuem um caráter tão restritivo e coercitivo quanto as próprias regras, com a diferença de que as regras nos são impostas de maneira mais explícita e, por vezes, mais desagradável, enquanto os valores são inculcados de maneira mais sutil, passam a fazer parte de nossa consciência, condicionando até o modo como vemos e sentimos a realidade que nos circunda. Isso pode ser observado, por exemplo, nos padrões sociais em relação ao corpo ou modos de vestimenta. Desta forma, percebemos o quão difícil é desejar algo além desses padrões, porque nos envolvem em todas as nossas dimensões, impõe-se a nós por todos os lados. Em resumo, aquilo que parece ser uma escolha é, na verdade, também uma forma de ausência de liberdade.

Por outro lado, tudo aquilo que consideramos como regra aparece sempre como imposição, como obrigação e dificilmente esconde o fato de tratar-se de uma prescrição alheia a nossa vontade, pois reconhece-se sempre a exterioridade de sua origem. No caso particular da regra moral, a obediência parece ainda mais incômoda, na medida em que não se trata de uma ação que se reverte imediatamente a nosso favor, - como, por exemplo, nos casos das regras de higiene - mas que temos que obedecer simplesmente porque assim nos dita a regra. Entretanto, é justamente por ter um caráter coercivo mais explícito que a regra permite perceber que se trata de uma imposição social, cujos mecanismo, finalidades e razões de ser podem ser compreendidos. Com isso, abre-se a possibilidade de agir de forma consciente, porque sabemos que se trata de uma regra social. Dessa forma, ao conhecer seus fundamentos e objetivos, somos capazes de julgar a pertinência desses fundamentos, questionando, inclusive, a validade atual de determinadas regras, contribuindo, na medida do possível, para conservá-las ou para renová-las. 
Portanto, a partir dessas considerações, é possível afirmar que os valores também podem ser considerados como regras, pois também prescrevem aquilo que devemos desejar, aquilo em que devemos acreditar, aquilo que devemos defender. Por outro lado, as regras também podem vir a se tornar valores, na medida em que reconhecemos que suas prescrições têm como finalidade garantir aquilo que consideramos um valor. Isso ocorre porque tanto a regra quanto o valor possuem uma mesma origem: a moral.

Como exemplo, podemos defender o fato de que, na sociedade brasileira, ao menos nos termos de nossa Constituição, a vida humana é considerada como o mais alto valor. Entretanto, para que esse valor seja respeitado, isto é, para que a vida de cada indivíduo seja respeitada, essa mesma Constituição define como regra que é absolutamente proibido matar um ser humano. Por tratar-se de um valor tão fundamental, o desrespeito a essa regra implica não apenas em uma sanção social - que é o desprezo pelo indivíduo que infringiu tal regra -, mas também uma sanção penal, que implica em uma dupla exclusão - uma exclusão moral no âmbito do convívio social e uma exclusão física, que dura o tempo que, em tese, a Justiça considera necessário para a reestruturação moral do indivíduo. Ao mesmo tempo, os muitos questionamentos a esse princípio que testemunhamos no Brasil contemporâneo revelam, em primeiro lugar, que esse valor não foi transmitido de forma eficaz por nosso sistema educacional, revelando um descompasso entre princípios constitucionais e os valores que circulam nos muitos grupos secundários. A relação entre educação e moral é tanto mais complexa e tensa quanto mais segmentada e diversa é a sociedade em questão.

Essa distinção entre regra e valor pode ser reconhecida na discussão que Durkheim realiza acerca dos dois aspectos da moral, quais sejam, o dever e o bem. Se, por um lado, a moral impõe-se como algo contrário à nossa vontade, por outro, nós, ao mesmo tempo, estimamos a regra moral. Isso porque sabemos que essas regras garantem a existência do grupo ao qual pertencemos e, por isso mesmo, é fonte de nossos valores, sendo investido de um caráter sagrado, isto é, inviolável e acima das coisas profanas, ordinárias ${ }^{1}$.

Esses elementos constitutivos da moralidade, aqueles mais gerais e constantes, devem estar presentes em toda e qualquer moral e têm como contrapartida no sujeito certas disposições subjetivas, que o autor chama de "espírito", querendo, com isso indicar o caminho que a educação deveria assumir em seu trabalho formativo. O espírito de disciplina, o espírito de adesão ao grupo e o espírito de autonomia são, portanto, a contrapartida individual da moralidade, cuja construção 
seria papel primordial da educação. É importante ressaltar que os dois primeiros elementos são comuns à moral como um todo, enquanto o último só é possível quando estamos diante de uma moral racional e laica, isto é, conforme as aspirações da sociedade de sua época.

O primeiro elemento refere-se ao espírito de disciplina e tem como fundamento:

[...] uma característica comum a todas as ações que comumente chamamos morais, que é o fato de que estas se dão segundo regras preestabelecidas. Conduzir-se moralmente é agir em conformidade com uma norma, que determina a conduta a ser seguida antes mesmo que tomemos partido acerca do que devemos fazer. O domínio da moral é o domínio do dever e o dever é uma ação prescrita (DURKHEIM, 2008a, p. 39).

Esse elemento tem como características centrais o gosto pela regularidade, a limitação do desejo, o esforço e o respeito à regra que inibe os impulsos. A regularidade envolve a necessidade de hábitos solidamente constituídos em uma sociedade, mas não se confunde com eles. $\mathrm{O}$ sentimento de regularidade é possível em virtude da autoridade que emana da moralidade, quando se percebe a ascendência exercida pela força moral. Isso é perceptível quando não seguimos ou quando violamos as regras morais e, a partir disso, podemos sofrer sanções das mais diversas formas.

No entanto, é importante destacar neste elemento, conforme coloca Durkheim, que, por mais que pareça, o “dever moral não é uma limitação destrutiva, que reduz o homem, mas, ao contrário, ajuda-o a viver de acordo com os parâmetros de normalidade" (WEISS, 2009, p. 180). O papel da moralidade pode ser entendido como uma forma de autocontrole do indivíduo, uma forma de moderar a nossa ação e nossos impulsos e de perceber nossas limitações, possibilitando a vida em sociedade. No fim, a noção de disciplina acaba se tornando uma condição de satisfação para quem a internaliza, pois, "quando nossas tendências são libertadas de todo comedimento, quando nada as limitam elas se tornam tirânicas e seu primeiro escravo é o próprio sujeito que as experimenta" (DURKHEIM, 2008a, p. 58).

O segundo elemento da moral, o espírito de adesão ao grupo, refere-se, de forma geral, à disposição do indivíduo em aderir à sociedade. Como já colocado, o sujeito se satisfaz e se constitui enquanto vinculado ao seu meio social, indo além dos seus fins pessoais ou da sua individualidade. Essa visão é bastante peculiar à concepção durkheimiana de moral, pois mostra que, ao construir vínculos afetivos com o grupo, que motivam seu pertencimento, o sujeito também acaba aderindo às suas regras e normas: a moral deixa de ser somente uma imposição, um dever, e passa a se tornar um bem, dado que essa inserção no grupo é algo que faz parte da própria natureza humana e pelo qual o sujeito tende a ter um apreço. De forma bas- 
tante simples, podemos afirmar que o ser humano só pode realizar-se plenamente quando vive coletivamente e, ao estabelecer nexos de afeto e interdependência com o grupo, passa a internalizar também a moral do grupo, processo protagonizado pela educação, mecanismo central para desenvolver nas crianças o gosto pela vida coletiva e as disposições necessárias para seguir as regras que tornam possível a existência do grupo. Afinal,

[...] a moralidade existe pelo simples fato de fazemos parte de um agrupamento humano, qualquer que seja ele. Mas, como o homem só é completo se faz parte de múltiplas sociedades, a própria moralidade só é completa na medida em que nos sentimos solidários a essas diversas sociedades das quais participamos (DURKHEIM, 2008a, p. 90).

O terceiro e último elemento é o espírito de autonomia, que deve ser formado no indivíduo para que este tome consciência das regras morais às quais se submete, e para que, conhecendo sua natureza e suas funções, seja capaz de entendê-las e transformá-las, sempre que julgar necessário. A autonomia, então, pode ser entendida como "a atitude do indivíduo que aceita a regra porque a reconhece racionalmente estabelecida" (FAUCONNET, 2013, p. 24), é o entendimento de uma autonomia da vontade racional, de compreender com a razão aquilo que é o bem, aquilo que é possível. Assim, conforme Durkheim (2008a, p. 121), entramos no âmbito de uma adesão esclarecida, em que "querer livremente não é querer aquilo que é absurdo; pelo contrário, é querer aquilo que é racional, é querer agir em conformidade com a natureza das coisas".

A proposta desse terceiro elemento deve ser entendida contra o pano de fundo do engajamento de Durkheim com a consolidação da Terceira República e a demanda de implementação de uma moralidade laica e racional. Esse comprometimento com as reformas nos sistemas de ensino justifica em grande medida o lugar central que a educação ocupou em sua obra e, sobretudo, explicam a presença de argumentos de caráter normativo em seus escritos. No seguinte trecho, encontramos uma definição que sintetiza muito bem como o autor entendia em que deveria consistir uma educação moral laica, sendo:

[...] uma educação que abdica de qualquer referência aos princípios sobre os quais repousam as religiões reveladas, que se apoia exclusivamente sobre ideias, sentimentos e práticas que se justificam unicamente pela razão, em uma palavra, uma educação puramente racionalista (DURKHEIM, 2008a, p. 19).

A moral, neste sentido, percebida e entendida como um fenômeno de origem social, instituída para os indivíduos, também deveria ser apreendida pelo viés da racionalidade. Entendemos que as regras morais são estabelecidas de acordo com 
as necessidades de cada coletividade, correspondendo àquilo que o meio social demanda para que seus membros possam viver em sociedade, garantindo uma forma de organização que lhe é própria. Em última instância, a sociedade é o fim, a fonte e a legitimidade da moral e esta se coloca, ao mesmo tempo, como o núcleo da vida coletiva, que influencia de maneira mais ou menos direta todos as suas dimensões, e à educação cabe o papel de transmitir esses princípios às novas gerações. A educação é, portanto, o dispositivo central de reprodução social, mas também de transformação social.

A escola, neste aspecto, seria responsável por desenvolver nos novos membros de uma sociedade as disposições fundamentais que a compõem, as suas bases morais e seus fundamentos. O espaço e os processos educacionais têm como finalidade preparar os indivíduos para viver no seu meio social, estabelecendo neles as disposições fundamentais para a vida em grupo. Ainda, especificamente na educação e na moralidade laica, edificada a partir dos anseios e das demandas da sociedade, o espírito de autonomia se coloca como possível, permitindo que se conheça a natureza da moralidade em questão, "para que se possa aderir a ela de forma espontânea e consciente, ou contribuir para que a moral encontre sua normalidade, caso se reconheça que ela está contrariando sua própria razão de ser” (WEISS, 2009, p. 185).

Assim, entendendo que uma base racional pode conferir verdadeira autonomia aos indivíduos, percebemos que todo o ensino encerra em si uma finalidade moral, pois, ao transmitir conhecimento, seja sobre o homem, seja sobre a natureza, o ensino contribui para a formação da racionalidade e da autonomia. A partir da defesa da necessidade de um ensino leigo da moral, os indivíduos poderiam alcançar gradualmente a consciência e a autonomia necessárias para compreenderem e transformarem a moral e as regras de sua sociedade, de acordo com o que lhes indicar a razão, fazendo com a sua socialização, no decorrer da vida, não esteja submetida a qualquer tipo de conformidade passiva, desinteressada ou acrítica.

\section{Conclusão: a educação como ação transformadora}

A educação se coloca na nossa frente como a forma direta de socialização, como fenômeno que nos instrui e nos permite viver em sociedade, fazendo com que compreendamos a necessidade das regras e limitações impostas e a importância da nossa vinculação aos grupos sociais existentes. Desta maneira, a educação se apresenta como um fenômeno central e essencial, tanto para a sociedade quanto para os indivíduos, pois cria uma relação de dependência entre estes. 
Para Durkheim, o que somos enquanto sujeitos é constituído a partir da nossa relação com o outro, ou seja, somos resultado das nossas interações e da internalização que fazemos do meio ao qual estamos inseridos. Nesse sentido, podemos entender quão difícil é desviarmos da sociedade em que vivemos, pois é dela que retiramos a base para tudo aquilo que fazemos ou pensamos. Entretanto, como já levantado anteriormente, isso não significa que estamos em um estado de passividade e aceitação daquilo que nos é colocado cotidianamente. A partir do momento em que introjetamos e absorvemos os elementos do meio e estes passam a fazer parte da nossa consciência individual, diferentes modificações podem ser construídas. De forma geral, entendemos que não somos constituídos de forma neutra; pelo contrário, somos continuamente influenciados pelas práticas e simbolismos que nos cercam, mas possuímos também, ao longo do nosso desenvolvimento, possibilidades de posicionamento - positivos ou negativos - perante o mundo.

O papel central da educação é, de certa maneira, permitir a continuidade e a manutenção do meio social, transmitindo a cada geração aquilo que já foi construído anteriormente. Mas entendemos também que, tanto por meio da formação de um pensamento autônomo nos novos sujeitos quanto de uma visão constantemente consciente do papel atribuído às gerações adultas como responsáveis por transmitir aquilo que a sociedade deseja, o processo educacional amplia seu papel de mero reprodutor daquilo que já existe e passa a ter um caráter transformador.

Neste sentido, lembrando que a educação e a moral correspondem àquilo que o contexto específico exige, percebemos que a nossa sociedade é composta e lida constantemente com diferentes visões de mundo e diferentes pressupostos, necessitando um tipo de vinculação que entenda a valorização da diferença como o ideal moral que permite a nossa existência atual enquanto coletividade. Sendo assim, da mesma maneira que Durkheim refletiu sobre a necessidade de mudanças na esfera educacional na sua época, devemos repensar as nossas formas de socialização e perguntar que paradigma de sujeito queremos instituir para saber lidar com toda diversidade que nasce e se consolida naturalmente em cada âmbito das nossas vidas individuais e coletivas.

\section{Nota}

1 Para uma discussão sobre o sentido do sagrado em Durkheim e sua relação com a moral, veja-se o texto de Rosati e Weiss (2015), em que se apresenta a proposta de uma atualização da sociologia da moral de matriz durkheimiana. 


\section{Referências}

DURKHEIM, Émile. A educação moral. Petrópolis: Vozes, 2008a.

DURKHEIM, Émile. As regras do método sociológico. São Paulo: Martin Claret, 2008b.

DURKHEIM, Émile. Da divisão do trabalho social. São Paulo: Martins Fontes, 2010.

DURKHEIM, Émile. Educação e sociologia. Petrópolis: Vozes, 2013.

DURKHEIM, Émile. Sociologia e filosofia. Rio de Janeiro: Forense, 1970.

FATURI, Rhuany. A produção acadêmica brasileira sobre a educação na obra de Émile Durkheim. Trabalho de Conclusão de Curso (Graduação em Ciências Sociais) - Universidade Federal do Rio Grande do Sul, Porto Alegre, 2014.

FAUCONNET, Paul. A obra pedagógica de Durkheim. In: DURKHEIM, Emile. Educação e sociologia. Petrópolis: Vozes, 2013. p. 09-41.

JONES, Susan Stedman. O individualismo. In: CONSOLIN, Marcia; WEISS, Raquel; OLIVEIRA, Marcio de. O individualismo e os intelectuais. Edição bilíngue e crítica. São Paulo: Editora USP, 2016. p. 85-94.

RODRIGUES, José (org.). Coleção Grandes Cientistas Sociais: Durkheim. São Paulo: Ática, 2010.

ROSATI, Massimo; WEISS, Raquel. Tradição e Autenticidade em um mundo pós-convencional. Sociologias, Porto Alegre, 2015, v. 17, n. 39, p. 110-159.

SELL, Carlos Eduardo. Sociologia clássica. Petrópolis: Vozes, 2013.

VARES, Sidnei Ferreira de. A educação como fato social: uma análise do pensamento pedagógico de Émile Durkheim. Revista de Educação UNG, v. 6, n. 1, p. 29-44, 2011.

VARES, Sidnei Ferreira de. A educação moral em Émile Durkheim. Dissertação (Mestrado em Educação) - Programa de Pós-Graduação em Educação, USP, São Paulo, 2008.

WEISS, Raquel. A concepção de educação de Durkheim como chave para a passagem entre o positivo e normativo. In: MASSELLA, Alexandre (org.). Durkheim: 150 anos. Belo Horizonte: Argvmentvm, 2009. p. 169-190. 